\title{
Methanol-Sensing Property Improvement of Mesostructured Zinc Oxide Prepared by the Nanocasting Strategy
}

\author{
Qian Gao, ${ }^{1}$ Wei-Tao Zheng, ${ }^{1}$ Cun-Di Wei, ${ }^{1}$ and Hui-Ming Lin ${ }^{2}$ \\ ${ }^{1}$ College of Material Science and Engineering, Jilin University, Changchun 130022, China \\ ${ }^{2}$ Key Laboratory of Semiconductor Nanocomposite Materials of Ministry of Education, \\ College of Chemistry and Chemical Engineering, Harbin Normal University, Harbin 150025, China \\ Correspondence should be addressed to Qian Gao; gaoqian@jlu.edu.cn and Hui-Ming Lin; hiuminglin@gmail.com
}

Received 20 December 2012; Accepted 9 January 2013

Academic Editor: Xiang Wu

Copyright (C) 2013 Qian Gao et al. This is an open access article distributed under the Creative Commons Attribution License, which permits unrestricted use, distribution, and reproduction in any medium, provided the original work is properly cited.

\begin{abstract}
The specific structure and morphology often play a critical role in governing the excellent intrinsic properties of the compound semiconductor. Herein, mesostructured $\mathrm{ZnO}$ with excellent methanol-sensing properties was prepared by a structure replication procedure through the incipient wetness technique. The investigation on the crystal structure and morphology of the resultant material shows that the product consists of hexagonally arranged mesopores and crystalline walls, and its structure is an ideal replication of CMK-3 template. Consequently, mesostructured $\mathrm{ZnO}$ was fabricated as a gas sensor for methanol. The excellent methanol-sensing performance was achieved at a relatively low operating temperature of $120^{\circ} \mathrm{C}$. In comparison with the nonporous $\mathrm{ZnO}$ prepared through conventional coprecipitation approach, mesostructured $\mathrm{ZnO}$ material shows the higher sensitivity and stability. Furthermore, it shows the discrimination between methanol and ethanol sensitivity, which makes it a good candidate in fabricating selective methanol sensor in practice.
\end{abstract}

\section{Introduction}

Zinc oxide has been widely investigated because of the hopes it raises for a wide range of technological applications such as catalysts $[1,2]$, transparent conductors [3], fieldemission devices [4], optoelectronic devices [5-7], and also for its fundamental scientific significance. However, besides its excellent intrinsic properties, the structure-activity relationship plays quite an important role in most of its numerous applications $[8,9]$.

As one important application, semiconducting zinc oxide is a promising material for sensing various gases [10-15]. Since semiconductor gas sensors are based on surfacechemical interaction between the gas molecules and the crystalline materials $[14,16]$. With large surface-to-volume ratios and well-defined pore structures, mesostructured metal oxides are particularly desired for improving sensing performance [17-19]. As we known, it is difficult to prepare mesostructured metal oxides by directing soft-template method. The hard template method makes it possible to synthesize mesostructured metal oxides with excellent gassensing properties [20-22]. At present, many mesostructured metal oxides have been obtained by the utilization of nanoporous silica as matrices, including $\operatorname{In}_{2} \mathrm{O}_{3}[18,23]$, $\mathrm{Fe}_{2} \mathrm{O}_{3}$ [24], $\mathrm{Co}_{3} \mathrm{O}_{4}[25,26]$, and $\mathrm{Cr}_{2} \mathrm{O}_{3}$ [26]. However, it is impossible to get $\mathrm{ZnO}$ mesostructures by nanocasting of mesoporous silica, because $\mathrm{ZnO}$ is an amphoteric oxide, and its structure will be destroyed in both acidic and alkali solution during the removal of the hard template. Although mesoporous carbon instead of silica could be used as structure matrix, the hydrophobic character of the carbon template is incompatible with the aqueous precursor solution. For the difficulty in obtaining $\mathrm{ZnO}$ with highly ordered mesostructures, the synthesis of ordered mesoporous $\mathrm{ZnO}$ through nanocasting was not reported until 2007 [27]. For this reason, to the best of our knowledge, few investigations on the sensing properties of ordered mesoporous $\mathrm{ZnO}$ have been reported [28].

In this research, the methanol-sensing properties of ordered mesoporous $\mathrm{ZnO}$ were investigated. As we known, 


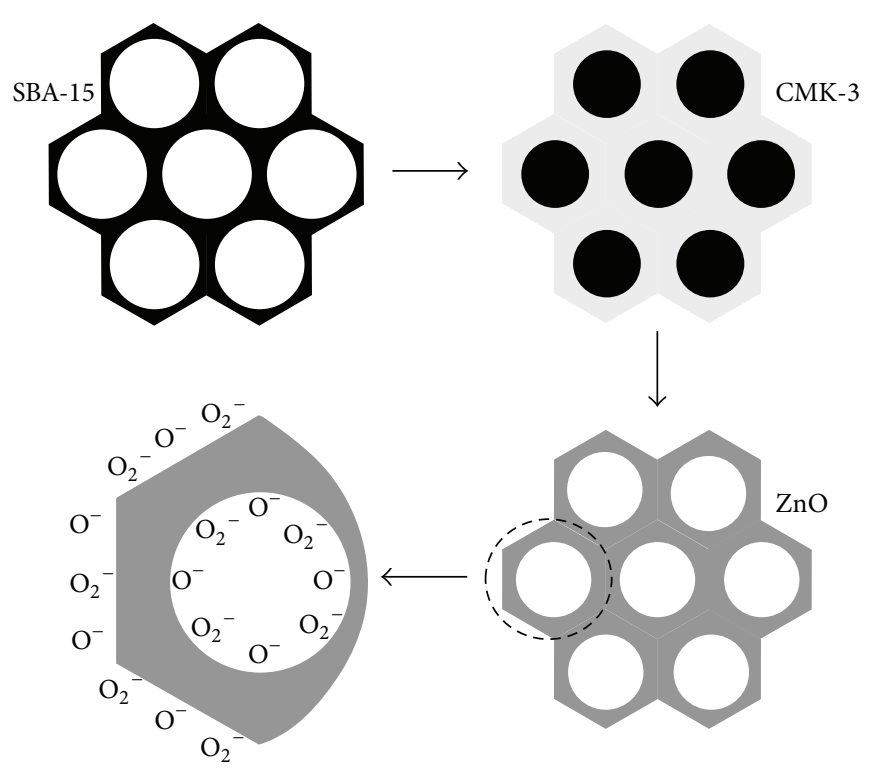

FIGURE 1: The nanocasting procedure for mesostructured $\mathrm{ZnO}$ synthesis.

methanol is a kind of widely used organic solvent with a broad application in power sources and the manufacturing of dyes, drugs, perfumes, and so forth. However, it is highly toxic and is often fatal to humans [29]. Thus, it is imperative to develop highly selective sensor for the detection of methanol. Herein, we present the synthesis of $\mathrm{ZnO}$ with ordered mesostructure for methanol sensor. The methanol-sensing test reveals that the sensor fabricated from mesostructured zinc oxide exhibits high sensitivity and selectivity towards methanol at a relatively low working temperature of $120^{\circ} \mathrm{C}$, which is much better than that of the corresponding nonporous materials synthesized by conventional approach.

Furthermore, in contrast to the reported $\mathrm{ZnO}$ materials which are applied as ethanol sensors [10, 13, 30, 31], this mesostructured $\mathrm{ZnO}$ material with uniform mesoporous structure shows higher response to methanol than ethanol without doping any additive and promoter. The discrimination between methanol and ethanol sensitivity makes it a good candidate in fabricating highly selective sensors in practice.

\section{Experiment Process}

2.1. Synthesis of Mesostructured $\mathrm{ZnO}$ Materials. The synthesis strategy is illustrated in Figure 1. SBA-15 was synthesized following the literature procedure reported by Zhao et al. [32]. A solution with $1.2 \mathrm{~g}$ of Pluronic P123 triblock copolymer, $30 \mathrm{~g}$ distilled $\mathrm{H}_{2} \mathrm{O}$, and $6 \mathrm{~mL}$ of concentrated $\mathrm{HCl}(35 \%)$ was prepared and stirred for $2 \mathrm{~h}$, and $5.4 \mathrm{~mL}$ of tetraethyl orthosilicate (TEOS) was added to the solution and stirred vigorously for $8 \mathrm{~min}$. Then the mixture was heated at $40^{\circ} \mathrm{C}$ for $24 \mathrm{~h}$ and $100^{\circ} \mathrm{C}$ for $48 \mathrm{~h}$ as a hydrothermal treatment. The solid product was filtered, washed, dried at room temperature, and calcined at $550^{\circ} \mathrm{C}$ for $6 \mathrm{~h}$. CMK-3 was prepared according to a literature procedure [33]; the silica matrix was removed by stirring in a $5 \% \mathrm{HF}$ solution. Mesostructured $\mathrm{ZnO}$ was prepared by incipient wetness impregnation of mesoporous CMK-3 carbon with zinc nitrate. To obtain a good infusion and filling of the zinc precursor into CMK-3 mesopores, a saturated ethanol solution of zinc nitrate was chosen as the precursor instead of aqueous solution. Using ethanol as a solvent can not only improve the wettability of CMK-3 but also facilitate the uniform loading of zinc nitrate into pores. The amount of the solution used in incipient wetness impregnation equals to the pore volume of the support. In order to convert zinc nitrate to zinc oxide, the sample was heated under an atmosphere of air to $300^{\circ} \mathrm{C}$ at a temperature ramp rate of $2^{\circ} \mathrm{C} \mathrm{min}-1$. The procedure was repeated twice, and the final product was obtained after heating in air at $700^{\circ} \mathrm{C}$ for 2 hrs.

For comparison, non-porous $\mathrm{ZnO}$ was synthesized as follows: $\mathrm{Zn}\left(\mathrm{NO}_{3}\right)_{2} \cdot 6 \mathrm{H}_{2} \mathrm{O}$ was dissolved in water to obtain a $0.1 \mathrm{M}$ solution, and then $0.2 \mathrm{M}$ urea aqueous solution was added to it. The mixture was gradually heated to $90^{\circ} \mathrm{C}$ with stirring until the emergence of a large amount of white precipitation. After washing and filtering, the precipitate was dried at $60^{\circ} \mathrm{C}$, followed by calcination at $500^{\circ} \mathrm{C}$.

2.2. Fabrication of Mesostructured $\mathrm{ZnO}$ Gas Sensor. For the preparation of the sensors, the as-synthesized product was mixed with deionized water to form a paste. Then the paste was coated on a ceramic tube on which a pair of $\mathrm{Au}$ electrodes was previously assembled. Pt wires attaching to these electrodes were used as electrodes. A Ni-Cr alloy wire was placed through the tube as a heater to provide the operating temperature. Figures 2(a) and 2(b) show a schematic image of the sensor element and a photograph of the as-fabricated sensor on a socket, respectively. 


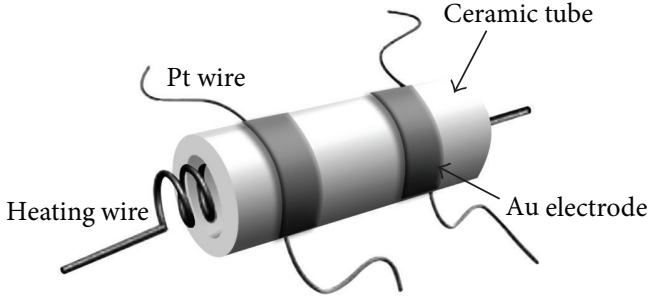

(a)

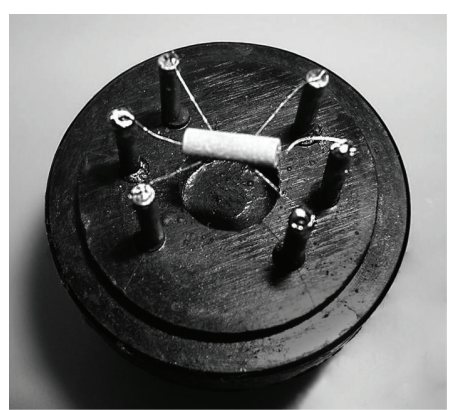

(b)

Figure 2: (a) Schematic image of the sensor element and (b) photograph of the as-fabricated sensor on a socket.

2.3. Characterization of Structure and Gas-Sensing Property. The structure of the product was investigated using an X-ray diffractometer (XRD) (Siemens D5005 diffractometer) with $\mathrm{Cu}-K_{\alpha}$ radiation at $40 \mathrm{kV}$ and $30 \mathrm{~mA}$. The TEM image was taken on a HITACHI H-600 transmission electron microscopic operating at an accelerating voltage of $100 \mathrm{kV}$. Nitrogen adsorption/desorption was measured with a Micromeritics ASAP 2010 M sorptometer.

Gas sensing properties were studied in a static test system. After injecting the saturated target vapour into a test chamber (about $1 \mathrm{~L}$ in volume), the sensor was arranged into the chamber. The resistance of the sensor was monitored by a measuring system, RQ-2 intelligent test meter (Qingdao, China). The gas sensitivity was defined as $R_{a} / R_{g}$, where $R_{a}$ is the resistance of the sensor in air, and $R_{g}$ is that in the detecting gas.

\section{Results and Discussion}

3.1. Characteristic of Sensing Material. In order to get the ordered mesostructured zinc oxide materials, CMK-3 and an organic solution of zinc nitrate were used as host matrix and precursor, respectively. The mesostructure of $\mathrm{ZnO}$ is formed by replicating the structure of CMK-3 template through the incipient wetness impregnation. As the interaction between the active precursor in solution and the CMK-3 carbon is weak, relatively high loading of precursor could be achieved by the method of incipient wetness impregnation which is more convenient, economical, and time saving than the traditional impregnation method [34]. Figure 3(a) presents the low-angle X-ray diffraction (XRD) patterns of the mesostructured $\mathrm{ZnO}$ sample, together with that of CMK-3 which was used as the template. The low-angle pattern of the resultant $\mathrm{ZnO}$ material clearly shows the characteristic diffraction, indicating that the mesoporous structure is formed. The XRD pattern of CMK-3 exhibits three characteristic peaks which are assigned to (100), (110), and (200) diffractions of the twodimensional hexagonal p $6 \mathrm{~mm}$ symmetry of the ordered pore system. The diffraction peak of mesostructured $\mathrm{ZnO}$ located at the same position as the carbon template further confirms that the hexagonal symmetry is preserved in the replication process, although a certain degree of broadening and a poorer resolution of the diffraction imply some loss in structural ordered degree.

The wide-angle powder XRD pattern of mesostructured $\mathrm{ZnO}$ is shown in Figure 3(b). The resultant mesostructured $\mathrm{ZnO}$ sample exhibits well-resolved characteristic diffraction peaks which are in accordance with the hexagonal wurtzitetype crystalline phase (JCPDS card number 79-0205). The well crystalline nature confirms the presence of crystalline framework walls in mesostructured zinc oxide.

Moreover, the structure of the resultant material is also verified by transmission electron microscopy (Figure 4 ). The TEM image viewed perpendicular to the direction of the hexagonal pore arrangement indicates that the structure of $\mathrm{ZnO}$ is an inverse replica of the carbon template. This replica is composed of a hexagonally packed nanoparticle array. Because of the confined growth in the channels of the mesoporous carbon template, the nanoparticles are rather uniform in diameter and oriented in the mesostructured framework. Upon removing the template, these nanoparticles interacted and constructed the mesoporous structure. Nitrogen physisorption reveals a mean pore diameter of $5.7 \mathrm{~nm}$, a specific surface area of $47 \mathrm{~m}^{2} \mathrm{~g}^{-1}$, and total pore volume of $0.21 \mathrm{~cm}^{3} \mathrm{~g}^{-1}$, while the specific surface area of nonporous $\mathrm{ZnO}$ used for contrast is only $13 \mathrm{~m}^{2} \mathrm{~g}^{-1}$.

\subsection{Gas-Sensing Properties}

3.2.1. Optimum Operating Temperature Property. Gassensing experiments were performed at different temperatures to find out the optimum operating condition for methanol detection. The optimum operating temperature is not only related to the intrinsic property of sensing material itself, but also related to the sensing process of the gas towards the surface of materials. The sensor fabricated from mesostructured zinc oxide was exposed to $50 \mathrm{ppm}$ methanol at different working temperatures to get the optimum condition. The relationship between the sensitivity and the working temperature is shown in Figure 5. It is seen that the value of the sensitivity increased quickly with the elevated working temperature until reached the maximum at $120^{\circ} \mathrm{C}$, and subsequently, it decreased rapidly with further elevated working temperature. Accordingly, a relatively low 


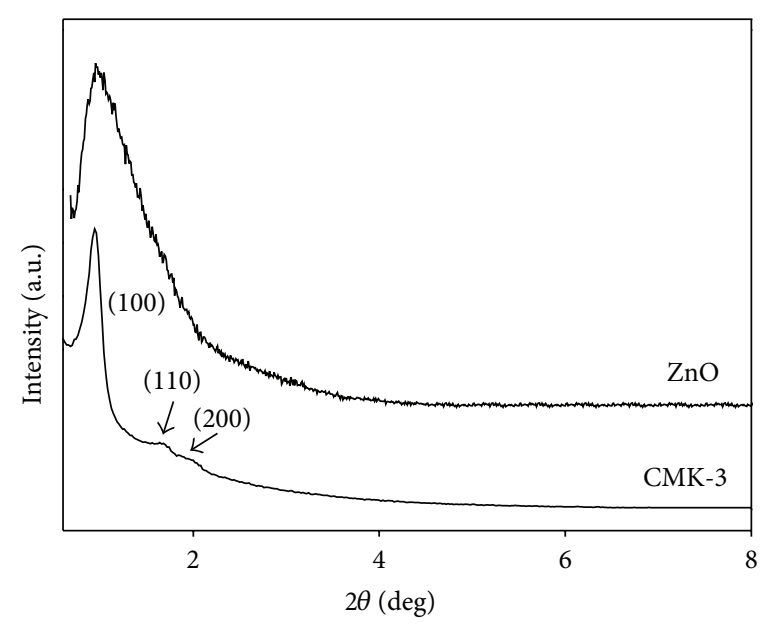

(a)

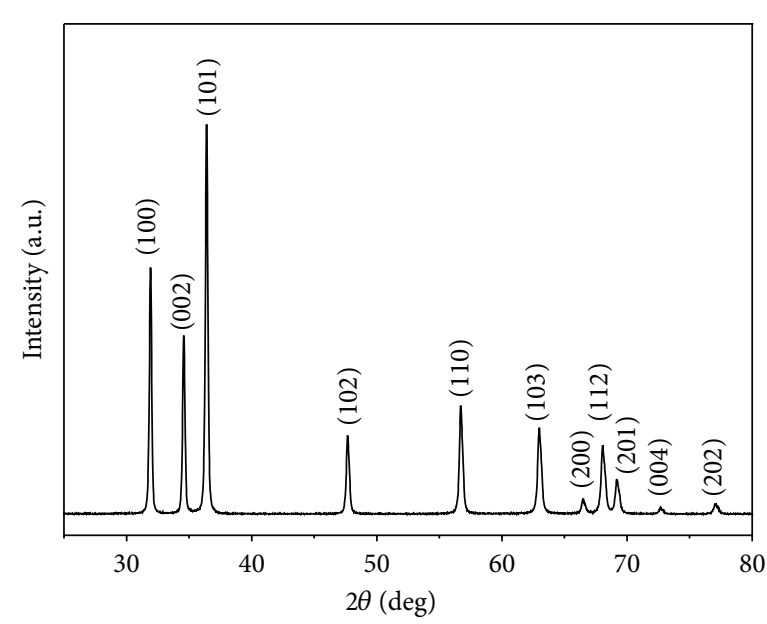

(b)

FIgURE 3: (a) Low-angle XRD patterns of mesostructured $\mathrm{ZnO}$ and CMK-3 which was used as the structure matrix and (b) wide-angle XRD pattern of mesostructured $\mathrm{ZnO}$.

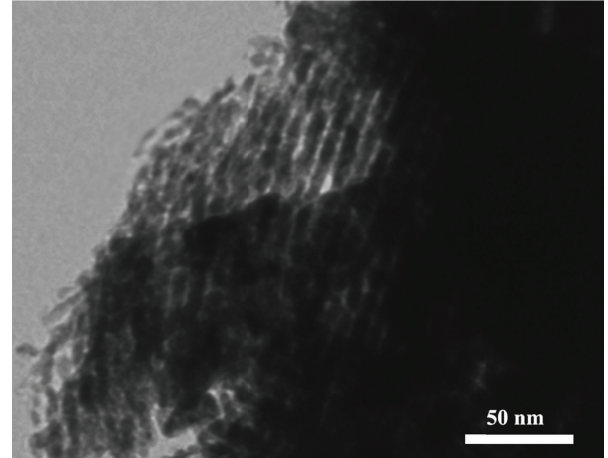

FIgURE 4: TEM image of the mesostructured $\mathrm{ZnO}$ prepared by a structure replication procedure.

operating temperature of $120^{\circ} \mathrm{C}$ is identified as the optimal working temperature and applied to all the gas-sensing measurements hereinafter.

3.2.2. Gas Response Property. As shown in Figure 6(a), the sensitivity of mesostructured $\mathrm{ZnO}$ versus methanol of different concentrations (5-1000 ppm) was measured. The sensor exhibits not only a high sensitivity to methanol, but also a good dependence on the concentration of methanol. In the low concentration range of 5-300 ppm in Figure 6(b), the sensitivity is linear and proportional to the methanol concentration. The liner equation is $S=0.755 C-2.184$, in which $S$ represents the gas sensitivity, and $C$ represents the methanol concentration. It is indicated that mesostructured zinc oxide is suitable for the detection of methanol at low concentrations. When gas response of the as-prepared gas sensor presents a linear or quasilinear relationship with the concentration of the measured gas, it means that the sensor can be used in the online monitoring of target gas. Moreover, for comparison, the sensitivity of non-porous $\mathrm{ZnO}$ versus

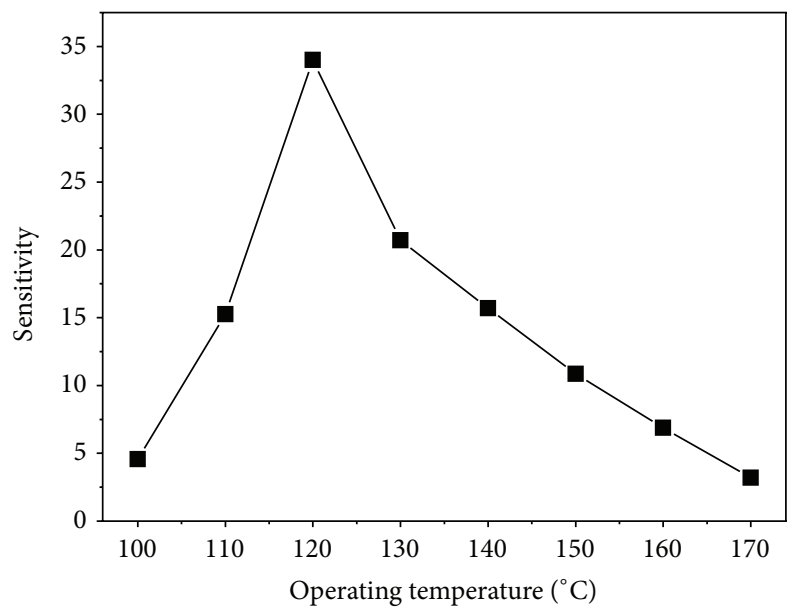

FIGURE 5: The operating temperature dependence of the sensitivity of mesostructured $\mathrm{ZnO}$ sensor to $50 \mathrm{ppm}$ methanol.

methanol gas of different concentrations is also recorded and shown in Figure 6. The sensitivity of non-porous $\mathrm{ZnO}$ to methanol is significantly lower than that of mesostructured $\mathrm{ZnO}$ under the same conditions. We assume that the higher methanol-sensing property of mesostructured $\mathrm{ZnO}$ is related to the ordered porous structure and the rigid structure matrix.

3.2.3. The Selectivity Property. The selectivity of mesostructured $\mathrm{ZnO}$ is investigated by exposure to $50 \mathrm{ppm}$ different gases $\left(\mathrm{C}_{2} \mathrm{H}_{5} \mathrm{OH}, \mathrm{CH}_{3} \mathrm{OH}, \mathrm{CO}, \mathrm{C}_{6} \mathrm{H}_{6}, \mathrm{HCHO}, \mathrm{NH}_{3}\right.$, and $\mathrm{H}_{2} \mathrm{O}$ ) (Figure 7). Obviously, mesostructured $\mathrm{ZnO}$ exhibits good sensitivity and high selectivity to methanol vapour compared with other gases. Remarkably, the sensitivity of mesostructured $\mathrm{ZnO}$ towards methanol is approximately 3.5 times higher than towards ethanol. It is presumed that 


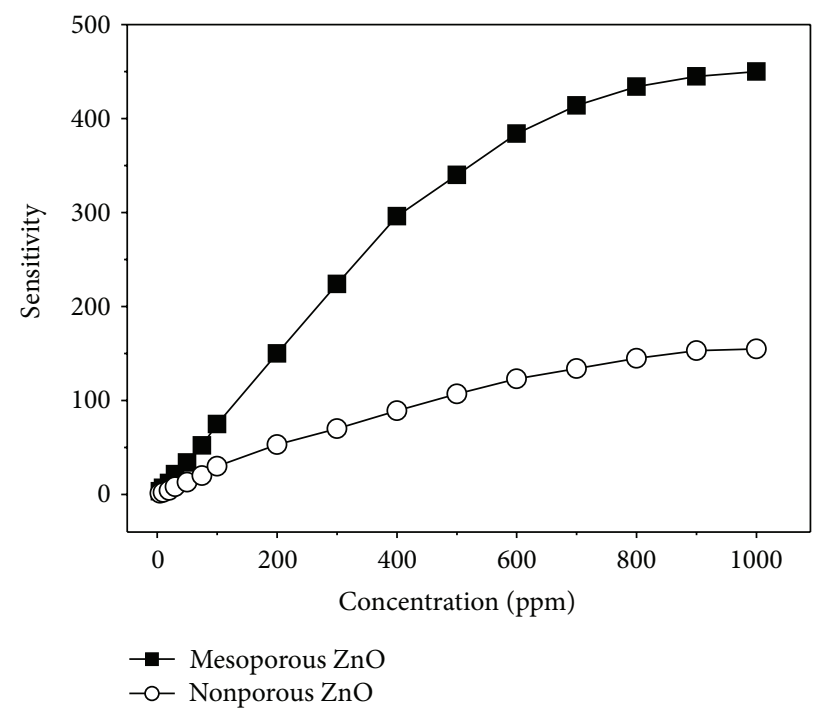

(a)

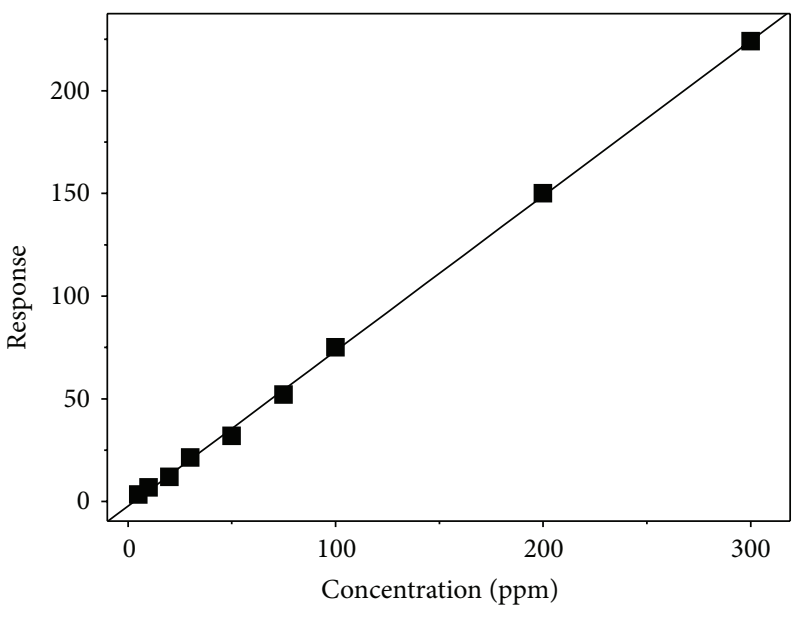

(b)

FIgURE 6: (a) The sensitivity of mesostructured $\mathrm{ZnO}$ sensor versus methanol concentration (5-1000 ppm) and (b) the calibration curve in the range of 5-300 ppm.

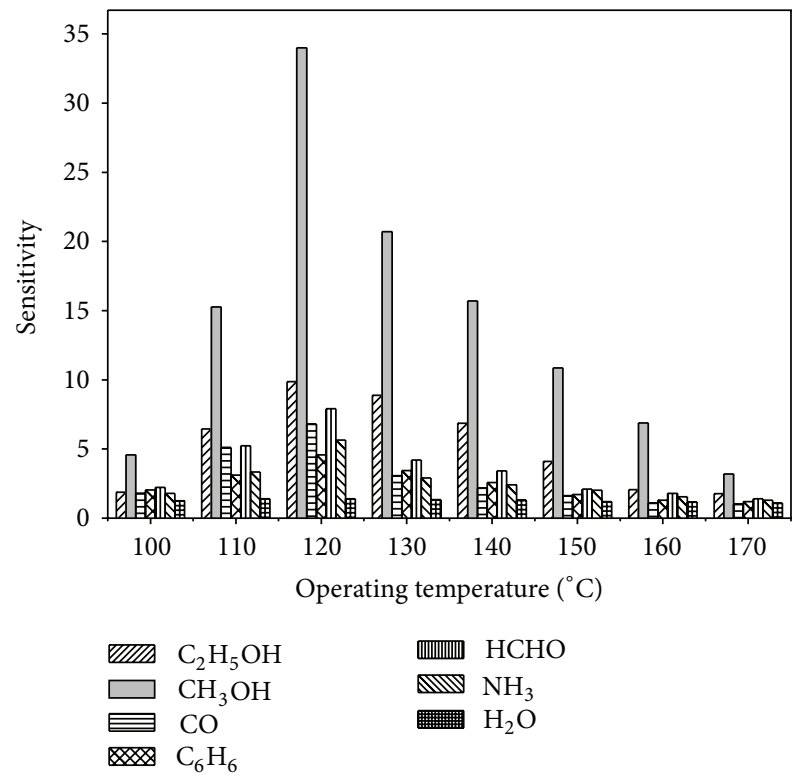

Figure 7: The sensitivity of the mesostructured $\mathrm{ZnO}$ sensor to $50 \mathrm{ppm} \mathrm{C}_{2} \mathrm{H}_{5} \mathrm{OH}, \mathrm{CH}_{3} \mathrm{OH}, \mathrm{CO}, \mathrm{C}_{6} \mathrm{H}_{6}, \mathrm{HCHO}, \mathrm{NH}_{3}$, and $\mathrm{H}_{2} \mathrm{O}$ at different operating temperature.

the methanol molecule is more suitable for diffusion in the mesopores, as the size of methanol molecule is smaller than that of ethanol molecule. It is well known that most of the applications of zinc oxide, including many of its excellent intrinsic properties, in general, rely critically on its specific structure and morphology. So, we believed that the high selectivity of mesostructured zinc oxide without doping any additive is due to the uniform mesoporous structure.

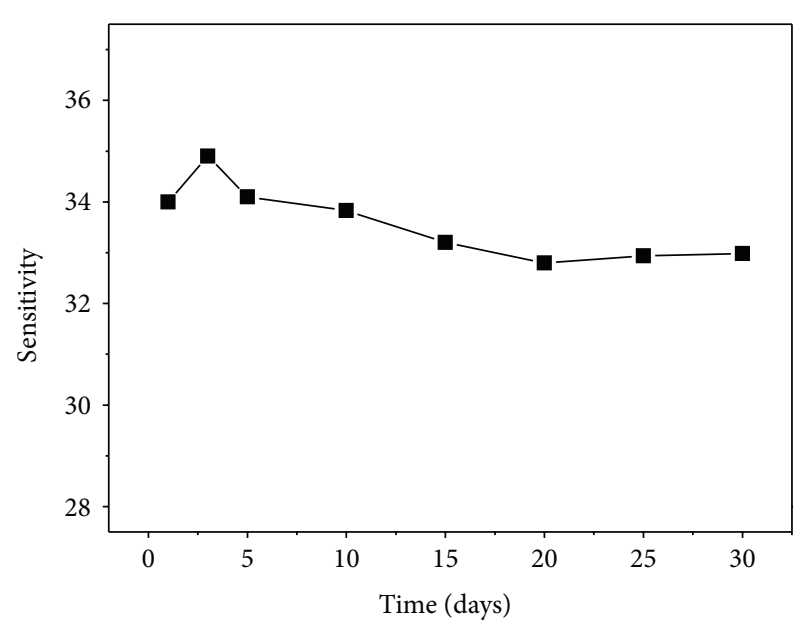

Figure 8: The long-term sensitivity values of mesostructured $\mathrm{ZnO}$ to $50 \mathrm{ppm}$ methanol at $120^{\circ} \mathrm{C}$.

3.2.4. Stability and Repeatability. The long-term stability of this sensor was investigated by repeating the test after aging. As shown in Figure 8, the sensor shows a nearly constant sensitivity to $50 \mathrm{ppm}$ methanol during the tests, indicating that the mesostructured $\mathrm{ZnO}$ sensor is extremely stable for detecting methanol. The superior sensitivity and selectivity combined with the high stability render the mesoporous $\mathrm{ZnO}$ promising material for practical application.

3.2.5. Gas-Sensing Mechanism. For most semiconductor metal oxides, gas sensing is based on surface-chemical interaction between gas molecules and the sensing material and reflected in the variation of resistance, which is primarily caused by the adsorption and desorption of the gas molecules 
on the surface of the sensor. In ambient air, the oxygen molecules are chemisorbed on the surface of $\mathrm{ZnO}$ to generate active oxygen species (Figure 1), such as $\mathrm{O}_{2}{ }^{-}$and $\mathrm{O}^{-}$, which results in the formation of the surface depletion region as follows:

$$
\begin{gathered}
\mathrm{O}_{2} \text { (gas) } \longleftrightarrow \mathrm{O}_{2} \text { (ads) } \\
\mathrm{O}_{2}(\text { ads })+\mathrm{e}^{-} \longleftrightarrow \mathrm{O}_{2}{ }^{-} \text {(ads) } \\
\mathrm{O}_{2}{ }^{-} \text {(ads) }+\mathrm{e}^{-} \longleftrightarrow 2 \mathrm{O}^{-} \text {(ads) }
\end{gathered}
$$

When the mesostructured $\mathrm{ZnO}$ is exposed to methanol vapour, the reaction between methanol and ionic oxygen species can take place in two possible ways [35] as follows:

$$
\begin{gathered}
\mathrm{CH}_{3} \mathrm{OH}+\mathrm{O}^{-} \longleftrightarrow \mathrm{HCHO}+\mathrm{H}_{2} \mathrm{O}+\mathrm{e}^{-} \\
\mathrm{CH}_{3} \mathrm{OH}+\mathrm{O}_{2}^{-} \longleftrightarrow \mathrm{HCOOH}+\mathrm{H}_{2} \mathrm{O}+\mathrm{e}^{-}
\end{gathered}
$$

Methanol molecules are oxidized to formaldehyde or formic acid step by step, and electrons are liberated accompanying the reactions, resulting in an increase of the carrier concentration and electronic conductivity of mesostructured zinc oxide. In comparison with non-porous $\mathrm{ZnO}$, mesostructured $\mathrm{ZnO}$ sensor exhibits superior methanol-sensing properties. The large surface-to-volume ratio and uncompacted structure are considered to facilitate the high sensitivity and favorable selectivity of the mesostructured $\mathrm{ZnO}$. Owing to their well-defined structure and effective electron transport, mesostructured $\mathrm{ZnO}$ materials are particularly suitable for the detection of methanol.

\section{Conclusions}

In conclusion, uniformed mesostructured $\mathrm{ZnO}$ with excellent sensing performance has been synthesized through an improved structure replication technique. It is revealed that the zinc oxides exhibit uniformly crystalline pore walls which are ideal replication of the template CMK-3 carbon, while the sensing process is considered to undergo a surface-chemical interaction mechanism between the methanol molecules and $\mathrm{ZnO}$ surface. The ordered pore system remarkably facilitates the improvement of sensitivity and selectivity for methanol sensing in contrast to the non-porous sensing materials. And also it is worth noting that the difference of the sensitivity between methanol and ethanol makes it a good candidate in potential practice. All in all, the mesostructured $\mathrm{ZnO}$ is a kind of promising materials for fabricating high performance in methanol sensors.

\section{Acknowledgments}

This work was supported by the Fundamental Research Funds for the Central Universities of China, cutting-edge science and interdisciplinary innovation projects of Jilin University (201103024), the Innovation Project of Jilin University Young Teachers, Foundation of Harbin Educational Committee (12521164), and National Natural Science Foundation of China (21101046).

\section{References}

[1] M. Behrens, F. Studt, I. Kasatkin et al., "The active site of methanol synthesis over $\mathrm{Cu} / \mathrm{ZnO} / \mathrm{Al}_{2} \mathrm{O}_{3}$ industrial catalysts," Science, vol. 336, no. 6083, pp. 893-897, 2012.

[2] P. L. Hansen, J. B. Wagner, S. Helveg, J. R. Rostrup-Nielsen, B. S. Clausen, and H. Topsøe, "Atom-resolved imaging of dynamic shape changes in supported copper nanocrystals," Science, vol. 295, no. 5562, pp. 2053-2055, 2002.

[3] S. Phadke, J.-Y. Lee, J. West, and A. Salleo, "Using alignment and 2D network simulations to study charge transport through doped $\mathrm{ZnO}$ nanowire thin film electrodes," Advanced Functional Materials, vol. 21, no. 24, pp. 4691-4697, 2011.

[4] Q. Zhao, H. Z. Zhang, Y. W. Zhu et al., "Morphological effects on the field emission of $\mathrm{ZnO}$ nanorod arrays," Applied Physics Letters, vol. 86, no. 20, Article ID 203115, pp. 1-3, 2005.

[5] F.-Y. Hung, T.-S. Lui, Y.-T. Chen, and R.-S. Xiao, "Electrical crystallization mechanism and interface characteristics of nanowire $\mathrm{ZnO} / \mathrm{Al}$ structures fabricated by the solution method," Journal of Nanomaterials, vol. 2012, Article ID 208362, 6 pages, 2012.

[6] H. Zhang, X. Wu, F. Qu, and G. Zhao, "ZnO microrod arrays grown on a curved sphere surface and their optical properties," CrystEngComm, vol. 13, no. 20, pp. 6114-6117, 2011.

[7] Y. Lei, F. Qu, and X. Wu, "Assembling $\mathrm{ZnO}$ nanorods into microflowers through a facile solution strategy: morphology control and cathodoluminescence properties," Nano-Micro Letters, vol. 4, no. 1, pp. 45-51, 2012.

[8] L. Yu, F. Qu, and X. Wu, "Solution synthesis and optimization of ZnO nanowindmills," Applied Surface Science, vol. 257, no. 17, pp. 7432-7435, 2011

[9] L. Gong, X. Wu, C. Ye, F. Qu, and M. An, "Aqueous phase approach to $\mathrm{ZnO}$ microspindles at low temperature," Journal of Alloys and Compounds, vol. 501, no. 2, pp. 375-379, 2010.

[10] Q. Wan, Q. H. Li, Y. J. Chen et al., "Fabrication and ethanol sensing characteristics of $\mathrm{ZnO}$ nanowire gas sensors," Applied Physics Letters, vol. 84, no. 18, pp. 3654-3656, 2004.

[11] X. Wang, J. Zhang, Z. Zhu, and J. Zhu, "Humidity sensing properties of $\mathrm{Pd}^{2+}$-doped $\mathrm{ZnO}$ nanotetrapods," Applied Surface Science, vol. 253, no. 6, pp. 3168-3173, 2007.

[12] N. Al-Hardan, M. J. Abdullah, and A. A. Aziz, "The gas response enhancement from $\mathrm{ZnO}$ film for $\mathrm{H}_{2}$ gas detection," Applied Surface Science, vol. 255, no. 17, pp. 7794-7797, 2009.

[13] H. Xu, X. Liu, D. Cui, M. Li, and M. Jiang, "A novel method for improving the performance of $\mathrm{ZnO}$ gas sensors," Sensors and Actuators B, vol. 114, no. 1, pp. 301-307, 2006.

[14] J. Xu, Q. Pan, Y. Shun, and Z. Tian, "Grain size control and gas sensing properties of $\mathrm{ZnO}$ gas sensor," Sensors and Actuators B, vol. 66, no. 1, pp. 277-279, 2000.

[15] C. M. Ghimbeu, J. Schoonman, M. Lumbreras, and M. Siadat, "Electrostatic spray deposited zinc oxide films for gas sensor applications," Applied Surface Science, vol. 253, no. 18, pp. 74837489, 2007.

[16] Y. Zeng, T. Zhang, H. Yang et al., "Preparation of $\mathrm{Cu}-\mathrm{Zn} / \mathrm{ZnO}$ core-shell nanocomposite by wire electrical explosion and precipitation process in aqueous solution and $\mathrm{CO}$ sensing properties," Applied Surface Science, vol. 255, no. 7, pp. 40454049, 2009.

[17] M. Tiemann, "Porous metal oxides as gas sensors," Chemistry, vol. 13, no. 30, pp. 8376-8388, 2007.

[18] T. Waitz, T. Wagner, T. Sauerwald, C. D. Kohl, and M. Tiemann, "Ordered mesoporous $\mathrm{In}_{2} \mathrm{O}_{3}$ : synthesis by structure replication 
and application as a methane gas sensor," Advanced Functional Materials, vol. 19, no. 4, pp. 653-661, 2009.

[19] N. S. Ramgir, Y. K. Hwang, S. H. Jhung et al., "CO sensor derived from mesostructured Au-doped $\mathrm{SnO}_{2}$ thin film," Applied Surface Science, vol. 252, no. 12, pp. 4298-4305, 2006.

[20] A. H. Lu and F. Schüth, "Nanocasting: a versatile strategy for creating nanostructured porous materials," Advanced Materials, vol. 18, no. 14, pp. 1793-1805, 2006.

[21] M. Tiemann, "Repeated templating," Chemistry of Materials, vol. 20, no. 3, pp. 961-971, 2008.

[22] H. Yang and D. Zhao, "Synthesis of replica mesostructures by the nanocasting strategy," Journal of Materials Chemistry, vol. 15, no. 12, pp. 1217-1231, 2005.

[23] H. Yang, Q. Shi, B. Tian et al., "One-step nanocasting synthesis of highly ordered single crystalline indium oxide nanowire arrays from mesostructured frameworks," Journal of the American Chemical Society, vol. 125, no. 16, pp. 4724-4725, 2003.

[24] F. Jiao, A. Harrison, J. C. Jumas, A. V. Chadwick, W. Kockelmann, and P. G. Bruce, "Ordered mesoporous $\mathrm{Fe}_{2} \mathrm{O}_{3}$ with crystalline walls," Journal of the American Chemical Society, vol. 128, no. 16, pp. 5468-5474, 2006.

[25] Y. Wang, C. M. Yang, W. Schmidt, B. Spliethoff, E. Bill, and F. Schüth, "Weakly ferromagnetic ordered mesoporous $\mathrm{Co}_{3} \mathrm{O}_{4}$ synthesized by nanocasting from vinyl-functionalized cubic Ia3d mesoporous silica," Advanced Materials, vol. 17, no. 1, pp. 53-56, 2005.

[26] C. Dickinson, W. Zhou, R. P. Hodgkins, Y. Shi, D. Zhao, and H. $\mathrm{He}$, "Formation mechanism of porous single-crystal $\mathrm{Cr}_{2} \mathrm{O}_{3}$ and $\mathrm{Co}_{3} \mathrm{O}_{4}$ templated by mesoporous silica," Chemistry of Materials, vol. 18, no. 13, pp. 3088-3095, 2006.

[27] T. Waitz, M. Tiemann, P. J. Klar, J. Sann, J. Stehr, and B. K. Meyer, "Crystalline $\mathrm{ZnO}$ with an enhanced surface area obtained by nanocasting," Applied Physics Letters, vol. 90, no. 12, Article ID 123108, 2007.

[28] T. Wagner, T. Waitz, J. Roggenbuck, M. Fröba, C. D. Kohl, and M. Tiemann, "Ordered mesoporous $\mathrm{ZnO}$ for gas sensing," Thin Solid Films, vol. 515, no. 23, pp. 8360-8363, 2007.

[29] P. Siciliano, "Preparation, characterisation and applications of thin films for gas sensors prepared by cheap chemical method," Sensors and Actuators B, vol. 70, no. 1-3, pp. 153-164, 2000.

[30] S. Choopun, A. Tubtimtae, T. Santhaveesuk, S. Nilphai, E. Wongrat, and N. Hongsith, "Zinc oxide nanostructures for applications as ethanol sensors and dye-sensitized solar cells," Applied Surface Science, vol. 256, no. 4, pp. 998-1002, 2009.

[31] C. S. Rout, S. Hari Krishna, S. R. C. Vivekchand, A. Govindaraj, and C. N. R. Rao, "Hydrogen and ethanol sensors based on $\mathrm{ZnO}$ nanorods, nanowires and nanotubes," Chemical Physics Letters, vol. 418, no. 4-6, pp. 586-590, 2006.

[32] D. Zhao, Q. Huo, J. Feng, B. F. Chmelka, and G. D. Stucky, "Nonionic triblock and star diblock copolymer and oligomeric sufactant syntheses of highly ordered, hydrothermally stable, mesoporous silica structures," Journal of the American Chemical Society, vol. 120, no. 24, pp. 6024-6036, 1998.

[33] S. Jun, S. H. Joo, R. Ryoo et al., "Synthesis of new, nanoporous carbon with hexagonally ordered mesostructure," Journal of the American Chemical Society, vol. 122, no. 43, pp. 10712-10713, 2000.

[34] J. A. Schwarz, C. Contescu, and A. Contescu, "Methods for preparation of catalytic materials," Chemical Reviews, vol. 95, no. 3, pp. 477-510, 1995.
[35] N. G. Patel, P. D. Patel, and V. S. Vaishnav, "Indium tin oxide (ITO) thin film gas sensor for detection of methanol at room temperature," Sensors and Actuators B, vol. 96, no. 1-2, pp. 180$189,2003$. 

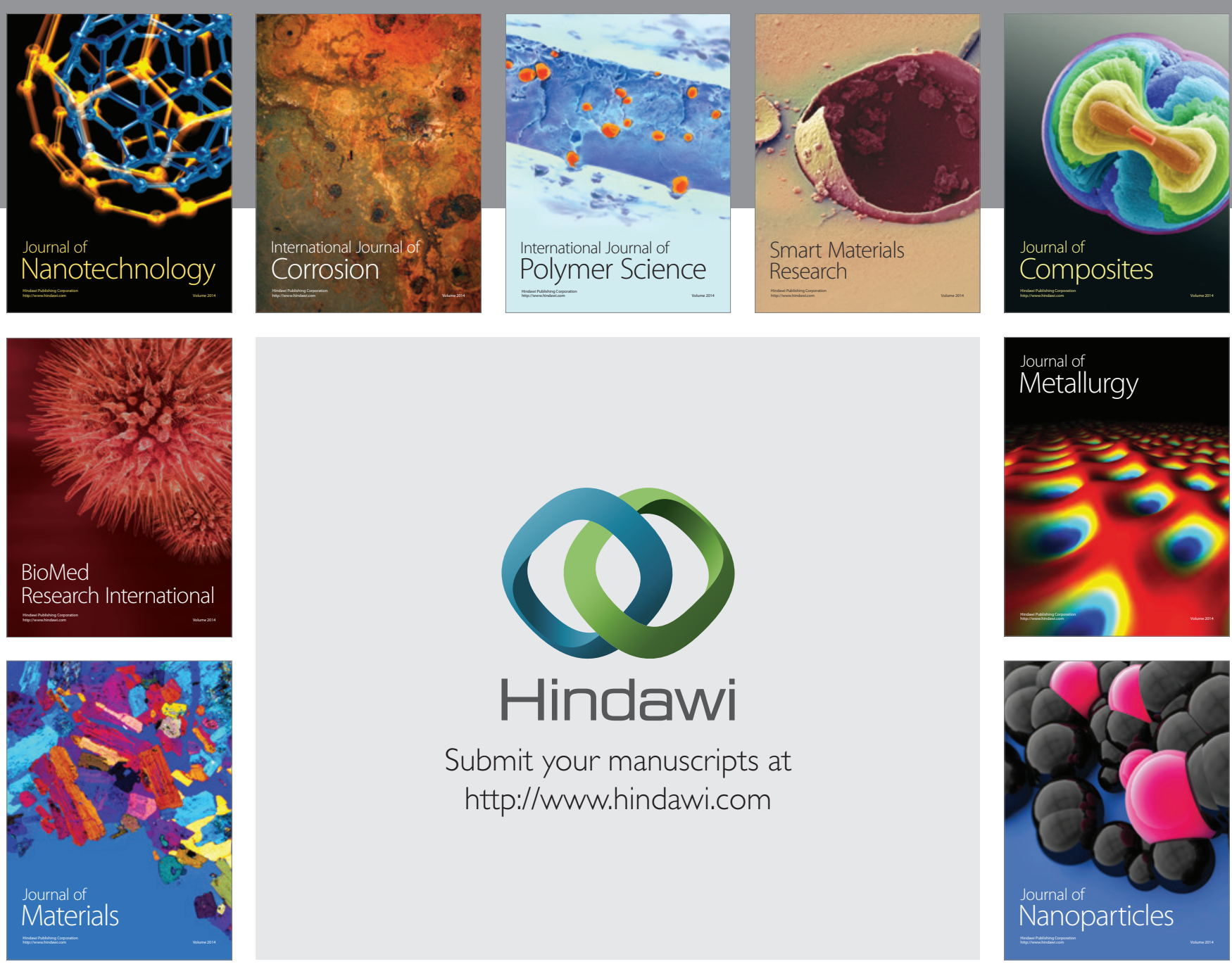

Submit your manuscripts at http://www.hindawi.com
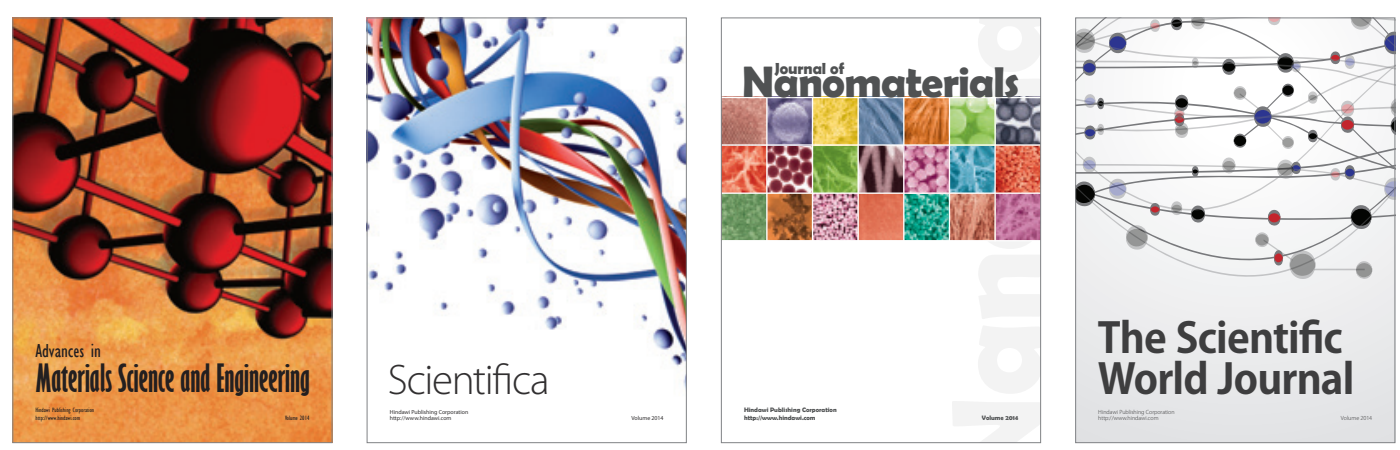

\section{The Scientific World Journal}
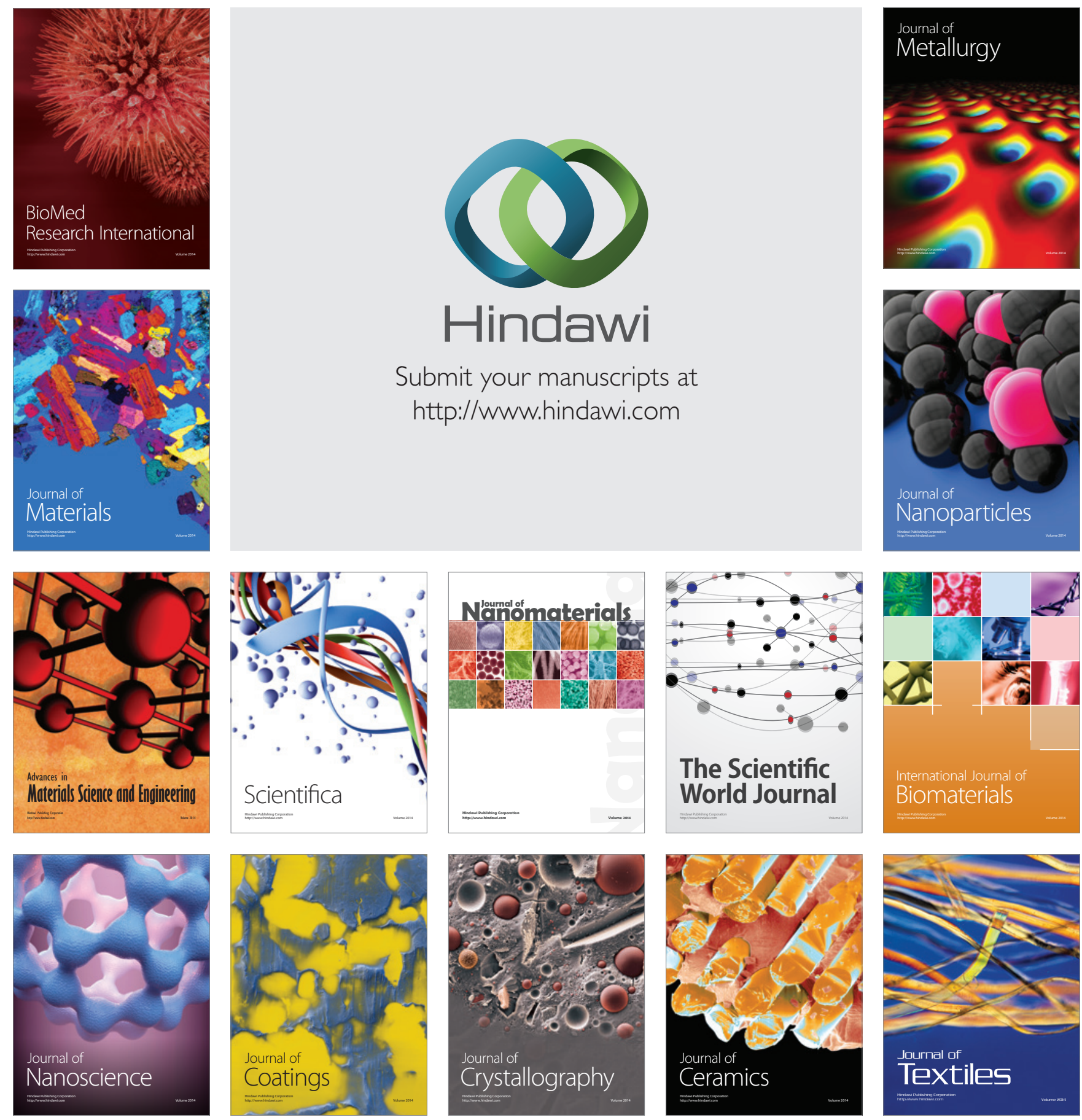